\title{
Temperature analysis on fire resistance experiments of partially encased beams
}

\author{
P. A. G. Piloto ${ }^{1}$, A. B. R. Gavilán ${ }^{2}$ \& L. M. R. Mesquita ${ }^{1}$ \\ ${ }^{I}$ Department of Applied Mechanics, Polytechnic Institute of Bragança, \\ Bragança, Portugal \\ ${ }^{2}$ Department of Mechanical Engineering, University of Salamanca, \\ Zamora, Spain
}

\begin{abstract}
Twelve fire resistance tests, grouped in four series, were developed using partially encased beams (PEB) without concrete slab, for different load level and shear connection. PEB were built with standard hot rolled IPE100 profile and reinforced concrete between flanges. Fire resistance was determined for standard ISO834 nominal heating curve, using small fire resistance furnace and portal frame. Temperature was measured in three different sections along PEB length, for three different materials (steel, concrete and reinforcement). Average temperature in each section and material was compared to the average over length temperature. Each series presented similar results, with good reproducibility. Special focus was given to critical temperature. The maximum temperature difference between sections S1, S2, S3 and the average element length temperature is smaller than $3.2 \%$ for test series 1 . For test series 2,3 and 4 the maximum temperature difference is smaller than $5.1 \%, 6.3 \%$ and $11.2 \%$, respectively. Temperature is not uniform in cross-section. After the initial heating stage, temperature revealed a constant difference of approximately $150^{\circ} \mathrm{C}$ between temperatures measured inside and outside, defining two main temperature evolutions. Temperatures measured outside revealed always higher temperature level.
\end{abstract}

Keywords: partially encased beams, fire resistance, critical temperature. 


\section{Introduction}

Partially-encased beams are elements in which the web of the steel section is encased by reinforced concrete. They are usually built-up with I-Shape or Hshape steel sections however they can also be constructed from thin-walled builtup sections. These elements are casted in the floor, and once the concrete cured, section behaves with composite action. Concrete between flanges provides several advantages over a steel beam, increasing fire-resistance, load bearing and stiffness, without enlarging the overall size of the cross section. These advantages outweigh the increased self-weight of the element.

Partially encased beams (PEB) have been widely tested at room temperature, but only a small number of experiments under fire conditions are reported.

Kindmann et al. [1] performed 13 tests on PEB with and without concrete slabs, proving the importance of the reinforced concrete between flanges for the ultimate bending moment. This research adjusted Eurocode for the design of partially encased composite beams.

Hosser et al. [2], carried out 4 experimental tests on simply supported composite PEB, connected to reinforced concrete slabs, under fire conditions. The research developed three-dimensional analytical model, sufficiently reliable in accuracy, to estimate the effective slab width.

In 1995, Plumier et al. [3] performed 12 full sized test joint specimens under cyclic loading, consisting of PEC connected to PEB. Authors concluded that neither the connection type (welded, bolted) nor the web thickness affected the performance of the specimen. Authors have also observed that yielding took place in the beams and that beam flanges always buckled outward due to the presence of concrete.

Lateral instability was investigated at room temperature by Lindner and Budassis [4], using 22 full-scale PEB with two different steel sections. A new design proposal for lateral torsional buckling was proposed, taking into account the torsional stiffness of concrete.

Maquoi et al. [5], improved and implemented the knowledge on lateral torsional buckling of beams, including PEB, and prepared design rules that were not satisfactory covered by the existing standards. The elastic critical moment and the ultimate lateral torsional buckling moment resistance were revised and improved.

Assi et al. [6] developed a theoretical and experimental study on the ultimate moment capacity of PEB. Authors performed 12 tests to investigate the contribution of different types of concrete. According to authors, normal concrete showed insignificant enhancement to flexural strength, when compared to lightweight concrete.

More recently, Kodaira et al. [7], decide to determine fire resistance of 8 PEB. Authors demonstrate that reinforcement is effective during fire. The numerical method did not well predicted experimental temperature, even though the global thermo-mechanical behaviour seemed to present results in good agreement. The performance criteria are not in accordance to the European 
standard [8], because Authors decided to use either deformation criterion or rate of deformation criterion to determine fire resistance.

In 2008, Elghazouli and Treadway [9] performed 10 full scale tests. The experimental analysis was focused on the inelastic performance or partially encased members. Authors discussed several parameters (strain hardening of steel, concrete confinement, extension of section yielding) related with capacity and ductility with relevance to design and assessment procedures.

Nardin and El Debs [10] studied the static behaviour of three composite PEB under flexural loading at room temperature, testing some alternative positions for shear studs, using mono-symmetric steel section. Experimental results confirmed that studs are responsible for composite action and increase bending strength.

The purpose of this study is to analyse temperature in three different sections of each PEB during fire resistance tests and evaluate the uniformity of heating inside furnace. The temperature of furnace environment was already been tested and numerically validated in a previous work [11], using sixteen plate thermocouples.

\section{Partially encased beams}

PEB are constructed by filling the space between the flanges of a steel profile with reinforced concrete. Partially encased sections can achieve higher fire resistance performance when compared to bare steel sections. The increase in fire resistance is due to the encased material, reducing the exposed steel surface area, introducing concrete which has a low thermal conductivity. Fire resistance can also be increased by reinforcement as reported in a previous work [12].

Partially encased beams were designed according to figure 1, using different types of mechanical connections to stirrups (welded and not welded).
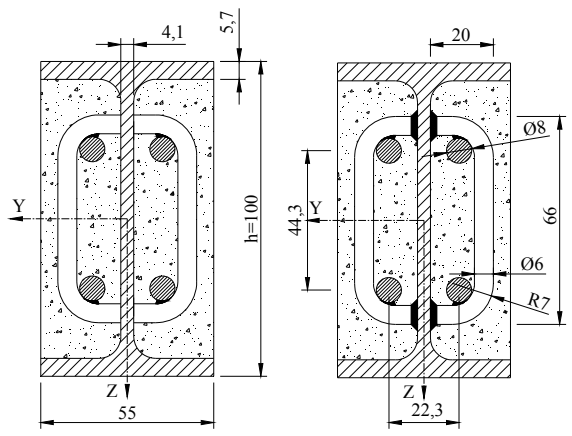

Figure 1: $\quad$ Cross section dimensions for PEB.

PEB were built with IPE100 steel S275 JR, using C20/25 encased concrete, with four longitudinal steel B500 rebars having a diameter of $8 \mathrm{~mm}$. Stirrups were designed and built with B500 rebars having a diameter of $6 \mathrm{~mm}$, distributed through the length, at a distance of $167 \mathrm{~mm}$. PEB were casted in laboratory, without the need of formwork and tested after more than 60 days, with respect to 
the first casting phase. The second casting phase was performed one week after the first. Surface of materials had not special treatment and were considered as delivered by manufactures. Steel elements were cut from long steel bars, using traditional machinery. Stirrups were welded (W) to the web of steel profile and not welded (NW). Reinforcement was welded to stirrups for the W case and tied with wire rope for the other case (NW).

\section{Fire resistance tests}

Partially encased beams were tested using to European standards [8], grouped in to four series, see table 1 . Three series were used to analyse the dependence on load level (40, 60 and $80 \%$ of plastic moment at room temperature, $\mathrm{M}_{\mathrm{pl}, \mathrm{Rd}}=13844$ $\mathrm{Nm}$ ); one series was prepared to compare the thermal and mechanical behaviour of PEB without welded stirrups (NW). Table 1 refers to the conditions of each test.

Each element was positioned inside the furnace for loading and heating, as represented in figure 2 . Tests were performed with constant mechanical load and increasing temperature according to the standard fire ISO834 curve.

Table 1: $\quad$ Series of fire resistance tests.

\begin{tabular}{ccccc}
\hline Series & $\begin{array}{c}\text { Specimen } \\
\text { Identification }\end{array}$ & $\begin{array}{c}\text { Stirrups } \\
{[\mathrm{W} / \mathrm{NW}]}\end{array}$ & $\begin{array}{c}\text { Thermal } \\
\text { Load }\end{array}$ & $\begin{array}{c}\text { Load level } \\
{\left[\% \mathrm{M}_{\mathrm{pl}}\right]}\end{array}$ \\
\hline \multirow{3}{*}{1} & $\mathrm{~B} / 1.2-01$ & $\mathrm{~W}$ & ISO834 & $40 \%$ \\
& $\mathrm{~B} / 1.2-02$ & $\mathrm{~W}$ & ISO834 & $40 \%$ \\
& $\mathrm{~B} / 1.2-03$ & $\mathrm{~W}$ & ISO834 & $40 \%$ \\
\hline \multirow{2}{*}{2} & $\mathrm{~B} / 1.2-04$ & $\mathrm{~W}$ & ISO834 & $80 \%$ \\
& $\mathrm{~B} / 1.2-05$ & $\mathrm{~W}$ & ISO834 & $80 \%$ \\
& $\mathrm{~B} / 1.2-06$ & $\mathrm{~W}$ & ISO834 & $80 \%$ \\
\hline \multirow{2}{*}{3} & $\mathrm{~B} / 1.2-07$ & $\mathrm{NW}$ & ISO834 & $80 \%$ \\
& $\mathrm{~B} / 1.2-08$ & $\mathrm{NW}$ & ISO834 & $80 \%$ \\
& $\mathrm{~B} / 1.2-09$ & $\mathrm{NW}$ & ISO834 & $80 \%$ \\
\hline \multirow{3}{*}{4} & $\mathrm{~B} / 1.2-10$ & $\mathrm{~W}$ & ISO834 & $60 \%$ \\
& $\mathrm{~B} / 1.2-11$ & $\mathrm{~W}$ & ISO834 & $60 \%$ \\
& $\mathrm{~B} / 1.2-12$ & $\mathrm{~W}$ & ISO834 & $60 \%$ \\
\hline
\end{tabular}

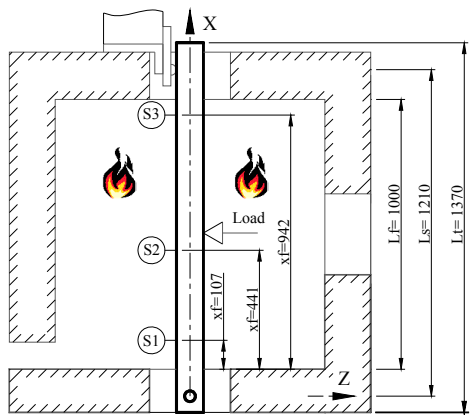

Figure 2: $\quad$ Testing conditions and main cross sections. 
The distance between supports of each PEB was "Ls"=1.210 m. Two different supports were applied; the top support restrained $\mathrm{Z} / \mathrm{Y}$ displacements and $\mathrm{X}$ rotation, while the bottom support restrained $\mathrm{Z} / \mathrm{Y}$ displacement and $\mathrm{Z} / \mathrm{X}$ rotations. The latest was built with a shaft suited into drilled web. The length exposed to fire "Lf" was equal to $1.0 \mathrm{~m}$, while the total length "Lt" of each specimen was defined to $1.37 \mathrm{~m}$.

Three different cross sections were defined to measure temperature (S1-S2S3).

The objective of determining fire resistance is to assess the behaviour of PEB when submitted to heating and load fire conditions. The method is able to quantify the ability of an element to withstand load when exposure to high temperatures, using appropriate performance criteria. Fire resistance may be expressed as the time or in temperature (critical) for which the appropriate criteria have been satisfied.

\subsection{Instrumentation}

Thermocouples type $\mathrm{K}$ were positioned along the length of each PEB, according to figure 3, using the spot welding machine. For concrete temperature readings in positions $\mathrm{Si}-\mathrm{IC}$ and $\mathrm{Si}-\mathrm{OC}$, thermocouples were welded to a small steel washer, wrapped in concrete.

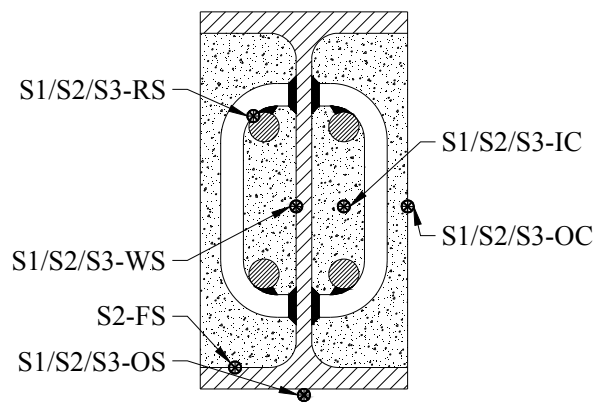

Figure 3: Thermocouples positions at three different cross sections.

Temperatures in materials were acquired with frequency of $2[\mathrm{~Hz}]$, using MGCPlus multichannel electronic measurement unit.

Temperature in furnace was acquired with $0.5[\mathrm{~Hz}]$, with a plate thermocouple, which comprise an assembly of a folded steel plate. The plate thermometer has the ability to measure the correct ratio of convective and radiative heat transfer for a flat surface.

\subsection{Material properties}

The mechanical properties were determined by tensile testing, according to international standards for hot rolled and cold formed steel, see table 2. Three samples were collected from the web of steel hot rolled profile and two more 
samples were collected from steel reinforcement material. Table 2 accounts for the modulus of elasticity " $E$ ", the proof strength " $R_{\mathrm{p} .0 .2 \%}$ ", maximum value of stress prior to the first decrease in force " $R_{E h}$ ", lowest value of stress during plastic yielding " $\mathrm{R}_{\mathrm{eL}}$ ", tensile strength " $\mathrm{R}_{\mathrm{m}}$ " and percentage of total extension at fracture " $\mathrm{A}_{\mathrm{t}}$ ".

Table 2: $\quad$ Tensile tests for hot rolled and cold formed steel.

\begin{tabular}{ccccc}
\hline Properties & Steel profile & & Steel reinforcement & \\
\hline & Average & Std. Deviation & Average & Std. Deviation \\
\hline E [GPa] & 197.901 & 2.948 & 203.294 & 2.110 \\
$\mathrm{R}_{\mathrm{p} .0 .2 \%}[\mathrm{MPa}]$ & 300.738 & 6.720 & 524.993 & 3.521 \\
$\mathrm{ReH}[\mathrm{MPa}](\mathrm{fy})$ & 302.466 & 5.749 & 531.508 & 7.908 \\
$\mathrm{ReL}[\mathrm{MPa}]$ & 300.856 & 4.028 & 520.825 & 4.068 \\
$\mathrm{Rm}[\mathrm{MPa}](\mathrm{fu})$ & 431.252 & 5.020 & 626.574 & 11.539 \\
At $[\%]$ & 41.584 & 0.231 & 25.155 & 0.495 \\
\hline
\end{tabular}

The thermal properties were not measured but were assumed from EN19921.2 [13] and from EN1993-1-2 [14]. Particular attention was dedicated to thermal resistance of interface between both materials. Authors verified that thermal conductance equal to $80 \mathrm{~kW} / \mathrm{m}^{2}$ was acceptable for validation of experiments [15].

\subsection{Performance criteria}

The performance criteria used for load bearing (rating R) are independent of the ultimate limit state attained by each partially encased beam. Fire resistance time was defined by the elapsed time between the start of heating and the failure of load bearing capacity.

The load bearing criteria or performance criteria were defined according to testing standards [8], using the displacement parameter " $D$ " and rate of displacement parameter "dD/dt" criteria. The ultimate limit state was considered when both parameters exceeded limits, eqn. (1).

$$
\begin{aligned}
& D=L^{2} / 400 d \quad[\mathrm{~mm}] \\
& d D / d t=L^{2} / 9000 d \quad[\mathrm{~mm} / \mathrm{min}] \quad(\text { if } D \geq L / 30)
\end{aligned}
$$

The performance criteria were used to determine critical temperature " $\theta_{\text {cr,d }}$ " and fire resistance time. This is the time in completed minutes for which the test specimen was able to support the test load.

\subsection{Temperature measurements}

The nominal fire heating curve ISO834 was used for heating PEB elements. Temperature was registered in three different sections, S1, S2 and S3, to verify the homogeneity of heating produced by fire resistance furnace. The maximum temperature difference between sections S1, S2, S3 and the average element temperature is smaller than $3.2 \%$ for test series 1 . For test series 2,3 and 4 the 
maximum temperature difference is smaller than $5.1 \%, 6.3 \%$ and $11.2 \%$, respectively.

Temperature is not uniform over the cross-section; after the initial heating stage, temperature evolution revealed a constant difference of approximately 150 ${ }^{\circ} \mathrm{C}$ between temperatures measured inside and outside each section, defining two main temperature evolutions. Temperatures measured outside revealed always higher temperature levels. The initial oscillation in temperature was due to the moisture effect in concrete. Figures 4-7 represent temperature evolution in section $\mathrm{S} 2$ for each tests series.

Test B/1.2-09 presented higher cracks when compared with other tests, reason why temperature increased inside concrete, in comparison with previous tests series 2 .

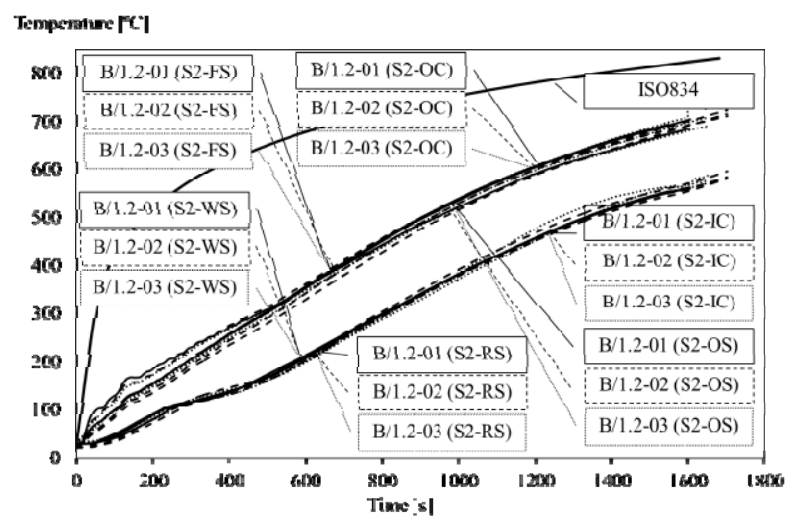

Figure 4: $\quad$ Temperature in section S2, for series 1.

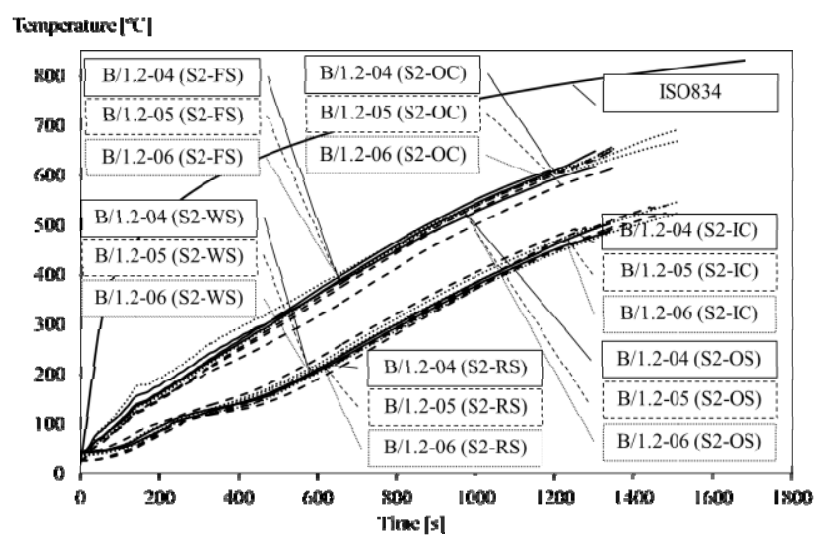

Figure 5: $\quad$ Temperature in section S2, for series 2. 


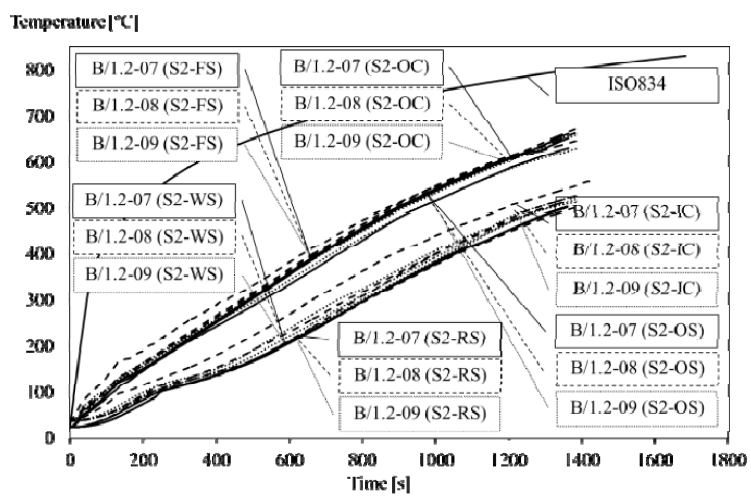

Figure 6: $\quad$ Temperature in section S2, for series 3 .

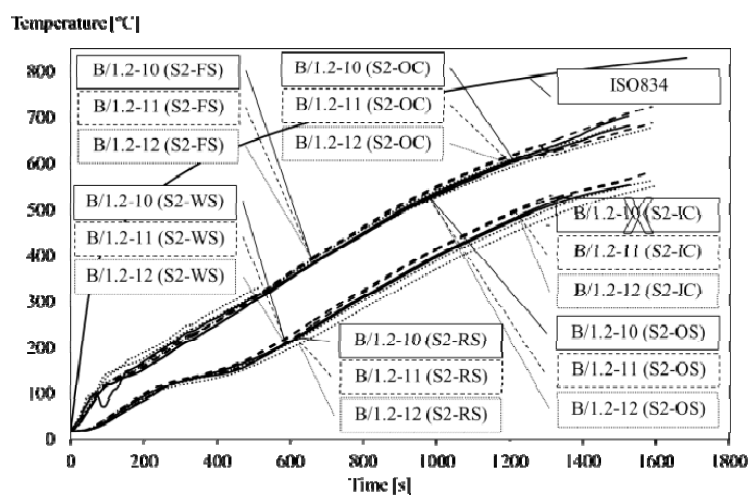

Figure 7: $\quad$ Temperature in section S2, for series 4.

Test B/1.2-10, from series 4 , missed temperature readings inside concrete in section $\mathrm{S} 2$.

Figures 8-11 represent the temperature distribution in each element according to each series. Critical temperature was determined for each material by weighted average based on temperature readings and the area contribution for each reading. "Tis", "Tic" and "Tir" refer to steel, concrete and reinforcement critical temperatures, determined for section "Si" $(\mathrm{i}=1,2,3)$, respectively, according to the following expressions, eqn. (2).

$$
\begin{gathered}
\operatorname{TiS}=(2 A f(\operatorname{SiOS})+\operatorname{Aw}(\operatorname{SiWS})) /(2 A f+A w) \\
\operatorname{Tic}=[1 / 4 A c(\operatorname{SiIC})+3 / 8 A c(\operatorname{SiIC}+\operatorname{SiOC})+3 / 8 A c(\operatorname{SiIC}+\operatorname{SiOS})] /(A c) \\
\operatorname{Tir}=\operatorname{SiRS}
\end{gathered}
$$

where "Af" is the area of the flange, "Aw" is the area of the web, "Ac" is the concrete area, "Ar" is the reinforcement area and "At" is the total cross section 
area. Critical temperature "TSi" was determined for each section "Si", based on area weighted average temperature, according to eqn. (3)

$$
T S i=[\operatorname{Tis}(A w+2 A f)+\operatorname{Tic}(A c)+\operatorname{Tir}(A r)] / A t
$$

Critical temperature " $\theta_{\text {cr,d }}$ " for each PEB was determined using the critical temperature of each section, eqn. (4), based on weighted temperature of each section TSi.

$$
\theta_{c r, d}=[T S 1+2 T S 2+T S 3] / 4
$$

Temperatures are represented up to the critical temperature by increments of 5 minutes.

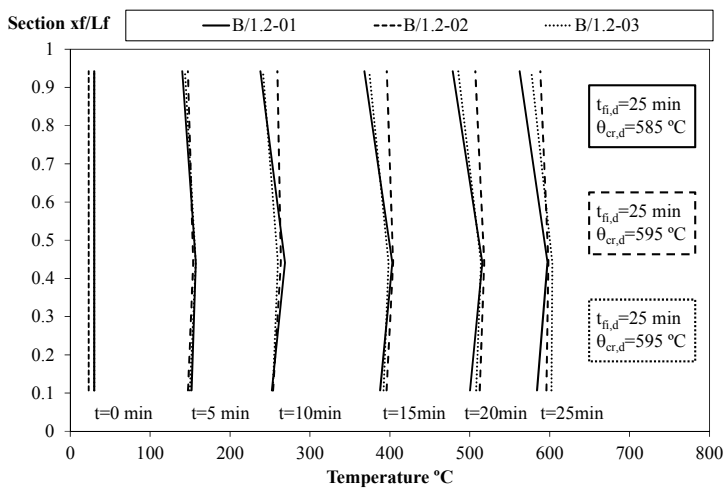

Figure 8: $\quad$ Temperature on exposed fire length for test series 1.

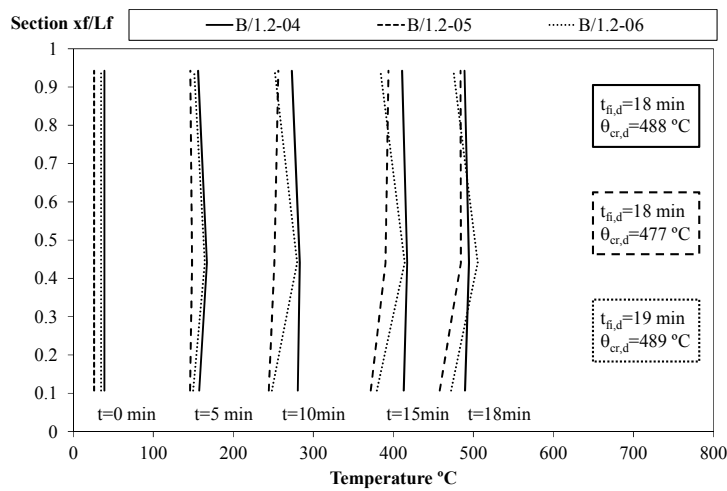

Figure 9: $\quad$ Temperature on exposed fire length for test series 2. 


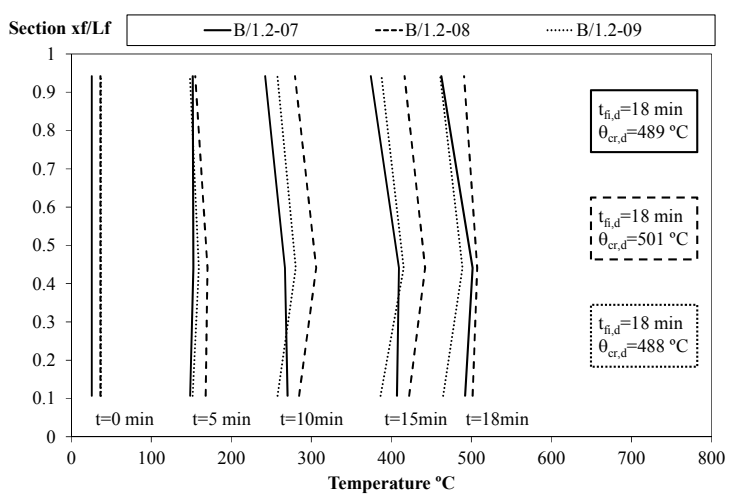

Figure 10: Temperature on exposed fire length for test series 3.

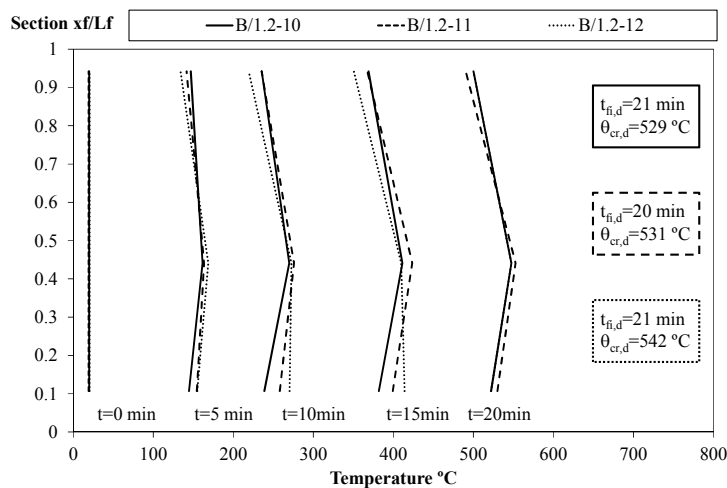

Figure 11: $\quad$ Temperature on exposed fire length for test series 4.

The deformation mode shape was the same for all three tests on series 1 . Ultimate limit state was attained by plastic hinge formation; after 20 minutes, the rate of displacement " $\mathrm{dD} / \mathrm{dt}$ " exceeded the limit criterion but did not verify the condition. Fire resistance time agrees very well, for all tests in 25 minutes. Temperature distribution is almost constant over each element.

The ultimate limit state for test series 2 was attained by instability (lateral torsional buckling); after 13 minutes, the rate of displacement was exceeded as well. Fire resistance time did not agree for all tests. 18 minutes were determined for tests B/1.2-04 and B/1.2-05, while 19 minutes was determined for test B/1.206. Temperature distribution is almost constant for each test, but different levels were determined for each registered time.

Fire resistance was also determined for different stirrup conditions. Series 3 differed from series 2 , because stirrups were not welded to the web of profile. Ultimate limit state was attained by lateral torsional buckling; after 13 minutes, the rate of displacement was exceeded, as well. Fire resistance time equals 
18 minutes for all tests in this series, although temperature distribution is not the same for each test.

Test series 4 was performed using 60\% load level, with stirrups welded to the web. The ultimate limit state was attained by the formation of a plastic hinge; after 16 minutes the rate of displacement was exceeded. Fire resistance time of 20 and 21 minutes were determined for tests on this series. Temperature distribution was almost equal for every tested beam.

Progressive damage of concrete was verified for each fire resistance test due to excessive deformation for longer fire exposure. Flexural cracking and debonding of concrete were observed at mid span. Encased concrete blocks presented expressive displacement outward of encasement (Y direction), as expected during tests series 3 .

\section{Conclusions}

Twelve bending tests were performed under fire standard ISO834 conditions to evaluate fire resistance and to determine the behaviour of partially encased elements. Three different load levels were considered (40, 60 and 80\%) and two different bond conditions were tested (welded and not welded).

Fire resistance depends on load level, as expected. Fire resistance decreased from 25 to 21 and 18 minutes, as load ratio increased from $40 \%$ to $60 \%$ and $80 \%$, respectively.

There was no evidence of shear bond effect. Tests in series 3 presented higher outward movement of concrete that was responsible for higher temperature inside cross section, but fire resistance was the same determined on series 2 .

Differences between temperatures along each element length were smaller than $10 \%$, respect to the element average critical temperature. Temperature of reinforcement represented the lowest value in all sections. Two different temperature evolutions were recorded for experiments, proofing that temperature was not uniform. Temperature distribution along each exposed PEB was almost constant proofing the uniformity of heating and the insulation at the supports.

Results provide essential data to the calibration and validation of new simplified design methods, tabulated data and advanced numerical methods.

\section{References}

[1] R. Kindmann, R. Bergmann, L. -G. Cajot, J. B. Scleich; "Effect of reinforced concrete between the flanges of the steel profile of partially encased composite beam"; Journal of Constructional Steel Research, 27, pp. 107-122, 1993.

[2] D. Hosser, T. Dorn, O. El-Nesr, "Experimental and numerical studies of composite beams exposed to fire", Journal of Structural Engineering, Vol. 120, No.10, pp. 2871-2892, 1994.

[3] A. Plumier, A. Abed, B. Tiliouine, "Increase of buckling resistance and ductility of H-sections by encased concrete", Behaviour of Steel Structures in Seismic Areas, E \& FN Spon, London, ISBN: 0419 198903, 1995. 
[4] Joachim Lindner, Nikos Budassis; "Lateral torsional buckling of partially encased composite beams without concrete slab"; Composite construction in steel and concrete $I V$, conference proceedings, May 28th to June 2nd, Banff, Alberta, Canada, pp. 117-128, 2000.

[5] R. Maquoi, C. Heck, V. Ville de Goyet, et al, (European commission), "Lateral torsional buckling in steel and composite beams"; ISBN 92-8946414-3; Book 1,2 and 3; Technical steel research final report EUR 20888 EN; August 2002.

[6] I.M. Assi, S.M. Abed, Y.M. Hunaiti, "Flexural strength of composite beams partially encased in lightweight concrete", Pakistan Journal of Applied Sciences 2(3), pp. 320-323, 2002.

[7] Akio Kodaira, Hideo Fujinaka, Hirokazu Ohashi and Toshihiko Nishimura; "Fire Resistance of Composite Beams Composed of Rolled Steel Profile Concreted Between Flanges"; Fire Science and Technology Vol.23 No.3, pp. 192-208, 2004.

[8] CEN, EN 1363-1, "Fire resistance tests, part 1- General requirements"; English version, European Standard, 1999.

[9] A.Y. Elghazouli, J. Treadway. "Inelastic behaviour of composite members under combined bending and axial loading", Journal of Constructional Steel Research, 64, pp. 1008-1019, 2008.

[10] Silvana de Nardin, Ana Lucia H.C. El Debs, "Study of partially encased composite beams with innovative position of stud bolts", Journal of Constructional Steel Research, Volume 65, Issue 2, pp. 342-350, February 2009.

[11] Paulo A.G. Piloto, Luís M.R. Mesquita, Alexandre Pereira; "Thermal Analysis in Fire-Resistance Furnace"; International workshop on Fire Protection and Life Safety in Buildings and Transportation Systems, proceedings ISBN 978-84-8102-559-0, pp 103-111, GIDAI - University of Cantabria, 15-17 October 2009.

[12] Piloto, P.A.G.; Gavilán, Ana Ramos; Mesquita, L.M.R.; “Advanced Numerical Method for Estimate Fire Resistance of Partially Encased Beams"; proceedings of the international congress in Fire Safety in Tall Buildings; ISBN 84-8102-415-5; pp 79-91; 19th October 2006, University of Cantabria, Santander, Spain.

[13] CEN - EN 1992-1-2; "Eurocode 2: Design of concrete structures - Part 1-2: General rules - Structural fire design”, European standards; Brussels, December 2004.

[14] CEN - EN 1993-1-2; "Eurocode 3: Design of steel structures - Part 1-2: General rules - Structural fire design", European standards; Brussels, April 2005.

[15] Piloto, P.A.G.; Ramos Gavilán, A.B.; Mesquita, L.M.R.; "Numerical analysis for thermal conductance of the interface between steel and concrete to composite structures at elevated temperatures", proceedings of the 2nd Portuguese conference on Numerical methods applied to Thermodynamics and Fluid Mechanics (in Portuguese), University of Aveiro, 8-9 May de 2008. 